Please quote as: Bittner, E. \& Leimeister, J. M. (2013): Why Shared Understanding Matters - Engineering a Collaboration Process for Shared Understanding to Improve Collaboration Effectiveness in Heterogeneous Teams. In: 46th Hawaii International Conference on System Sciences (HICSS), Maui, Hawaii. 


\section{Why Shared Understanding Matters - Engineering a Collaboration Process for Shared Understanding to Improve Collaboration Effectiveness in Heterogeneous Teams}

\author{
Eva Alice Christiane Bittner \\ Information Systems, Kassel University \\ eva.bittner@uni-kassel.de
}

\author{
Jan Marco Leimeister \\ Information Systems, Kassel University \\ leimeister@uni-kassel.de
}

\begin{abstract}
Solving complex problems often requires experience and perspectives of various, often heterogeneous experts. Shared understanding of the task is an important determinant for the performance of collaborative groups [1, 2]. Surprisingly little attention has been paid to the systematic development of processes that lead to a shared understanding within heterogeneous groups. To address this challenge, we provide a systematic, reusable process to support groups to converge towards a shared understanding of a task to be then able to collaborate more effectively and efficiently. To achieve the proposed goal, we develop a collaboration process grounded in theory based design guidelines, including activities for individual (1) and collaborative construction of meaning (2) as well as constructive conflict resolution (3). We ground our work in group cognition research and apply a collaboration engineering approach [3]. We test the process design in a computer-aided requirements elicitation workshop with experts from different professional backgrounds. We identify strengths and limitations of the process design to enable the development of thinkLets (reusable design patterns for collaboration engineering) for shared understanding in future research.
\end{abstract}

\section{Introduction}

In knowledge economies, organizational work has become increasingly complex and requires more and more diverse expertise. Research on group work has shown that collaboration is critical for organizational productivity, as many tasks exceed the cognitive capabilities of any individual, also due to their complexity [1]. Heterogeneous groups have been shown to outperform individuals in complex tasks, where a single person lacks the knowledge, skills and experience to solve it $[4,5]$. Diverse groups with people from various backgrounds, with different experience and areas of expertise can provide substantial potential, if complementary skills and knowledge can be integrated successfully. While the members involved in the group usually do not have to be experts in all fields tackled by the project, "they have to be able to integrate their knowledge bases in a sensible manner" [6].

What we refer to as "shared understanding" of the task is both an important determinant for performance as well as a challenge in heterogeneous groups. Group members might be using the same words for different concepts or different words for the same concepts without noticing [3]. They might be unaware of unshared individual knowledge which could be crucial for completing the task successfully. This can lead to substantial losses in efficiency in collaboration processes and suboptimal outcomes [79]. We aim to address this challenge by providing a structured collaboration process design based on theory grounded design guidelines that can be used to support heterogeneous groups to develop a shared understanding of an initially ill-defined task. With this paper we contribute to making the construction of shared understanding in heterogeneous groups more predictable and manageable. This is achieved by an overview of determinants of shared understanding, theory based design guidelines to ground systematic design efforts and a collaboration process that should lead to collaboration process design patterns for shared understanding.

\section{Related Work}

\subsection{Shared Understanding}

Confusion exists in literature, on the definition of shared understanding, it's antecedents and effects and how shared understanding can be operationalized and 
measured. Sharedness encompasses various aspects, e.g. "similarity, agreement, convergence, compatibility, commonality, consensus, consistency, and overlap" [10]. Two differing interpretations of "shared" can be found, namely shared as the joint possession of some resource versus the division of a resource between multiple recipients [11]. While the latter refers e.g. to the distribution of tasks or knowledge among different people, the former covers the phenomenon we see in shared understanding. Groups, who are engaged in collaborative work need to have some knowledge and understanding in common, which functions as a joint reference base, in order to work productively. Thus, we focus the definition of "shared" for our purpose as some resource being possessed jointly by several people. A definition of shared understanding should reflect this view.

"Understanding is an ability to exploit bodies of causal knowledge (i. e. knowledge about the antecedents and consequents of particular phenomena) for the purpose of accomplishing cognitive and behavioural goals." [11]. This definition of understanding highlights the importance of both knowledge as facts, and the structure of this knowledge. Causal knowledge is necessary for directed action towards the group goal. Seeing understanding as an ability, or "meaning in use" strengthens the viewpoint that understanding is more than knowledge, but involves reasoned action[10, 12]. Whereas knowledge refers more to understanding of a current reality, evaluative beliefs target expectations about an expected or aspired future state, which we consider especially important for collaborative tasks, where the goal or product is not pre-specified in detail. Thus, understanding is not static, but a dynamic state.

Combining the thoughts on sharedness and understanding discussed above, shared understanding is "the ability of multiple agents to coordinate their behaviours with respect to each other in order to support the realization of common goals or objectives" [11]. Based on the concept of joint possession of resources, this ability is based on "the overlap of understanding and concepts among group members" [13]. "Shared understanding refers to mutual knowledge, mutual beliefs, and mutual assumptions" [13].

Thus, we define shared understanding as an ability to coordinate behaviours towards common goals or objectives ("meaning in use" or action perspective) of multiple agents within a group (group level) based on mutual knowledge, beliefs and assumptions (content \& structure) on the task, the group, the process or the tools and technologies used (scope/object perspective) which may change through the course of the group work process due to various influence factors and impacts group work processes and outcomes.

The popular construct of shared/team mental models, although it is differentiated from shared understanding by some authors due to its stronger focus on command and control teams with highly structured tasks [9] and its lack of consideration of evaluative beliefs $[1,9]$, is closely related to shared understanding [14]. Therefore, we included team mental models research into our overview of related work, as long as it fits the definition of shared understanding described above.

\subsection{Determinants and Effects of Shared Understanding}

Positive effects of shared understanding in groups are discussed in prior work e.g. on performance (quality and quantity of group products) $[1,2]$ group member satisfaction [1], co-ordination [14], reduction of iterative loops and re-work [6], innovation [15] or team morale [8]. Kleinsmann et al.[15] also identify antecedents on an actor, project and company level, which are expected to influence the construction of shared understanding in groups. Langan-Fox et al. [1] distinguish between individual differences and environmental factors as determinants. Among the factors related to the individual and the group are e.g. individual personality and skills, team familiarity, authority, and diversity [15, 16]. Environmental factors such as physical proximity, incentives, communication support or organizational culture have also been discussed $[1,14,15,17]$. Furthermore, determinants concerning the collaboration process have been analysed [15] such as reasoning and communication, visualized beliefs and evidences, separation of individual and shared activity spaces, and training [8, 9, 17, 18]. For the purpose of this paper, process variables are of special interest, as they provide reference points for design choices. If techniques and processes can be applied that support the creation of shared understanding in heterogeneous groups, those groups are expected to gain efficiency in their work and produce better results.

Mohammed et al. note, that "in order for a team to achieve a shared, organized understanding of knowledge about key elements in the relevant environment, changes in the knowledge and/or behavior of team members will most likely occur. Therefore, group learning plays a significant role in the development, modification, and reinforcement of 
mental models" [9]. Some recent research has started to examine the relationship between interaction and group learning/shared understanding (see e.g. [19, 20]. However, a lack of knowledge can be identified concerning the specific patterns that lead to the construction of shared understanding [21]. Van den Bossche et al. have addressed this gap by developing and testing a model of the team learning behaviours leading to the construction of shared understanding (figure 1) [21]. This model constitutes the theoretical basis for our design guidelines and design decisions. It will be described in detail in section four.

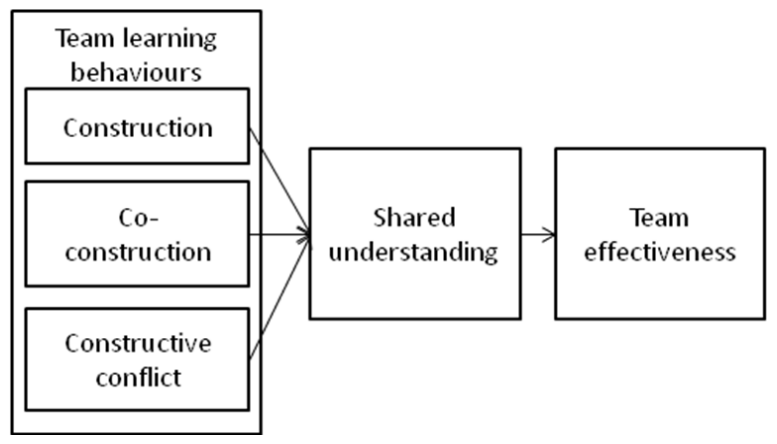

Figure 1: conceptual model (van den Bossche et al. 2011[21])

We focus on the antecedents in this model for the purpose of an initial design, as they are process variables and well specified. For later design iterations, other or additional antecedents presented in the overview might be considered.

\section{Method}

For developing the collaboration process, we followed the Collaboration Engineering design approach [22]. Collaboration Engineering addresses the challenge of designing and deploying collaborative work practices for high value recurring tasks [3]. As the construction of a shared understanding of ill-defined tasks is crucial for many collaborative tasks, high-value and recurring, it falls into the scope of collaboration engineering.

Much prior collaboration engineering research focuses on tasks for generation, evaluation etc, but little documented reusable procedures were found on how to support the "clarify" pattern of collaboration (see the FastFocus thinkLet in [23] for thinkLet aiming at clarification). Following Briggs 2006, to clarify means to "Move from having less to having more shared understanding of concepts and of the words and phrases used to express them" [24] and thus reflects processes for the construction of shared understanding. Although the core pattern involved in the construction of shared understanding is "clarify", we are using a broader perspective on the process of building shared understanding than Briggs' definition reflects. Therefore, other patterns are likely to be involved in this process.

Briggs (2006) argues, that grounding collaboration process design in good theory can enable unexpected success, as it can lead to nonintuitive design choices. Causal relationships described in theory provide designers of collaboration processes with hints for options they would not have considered without the theory.

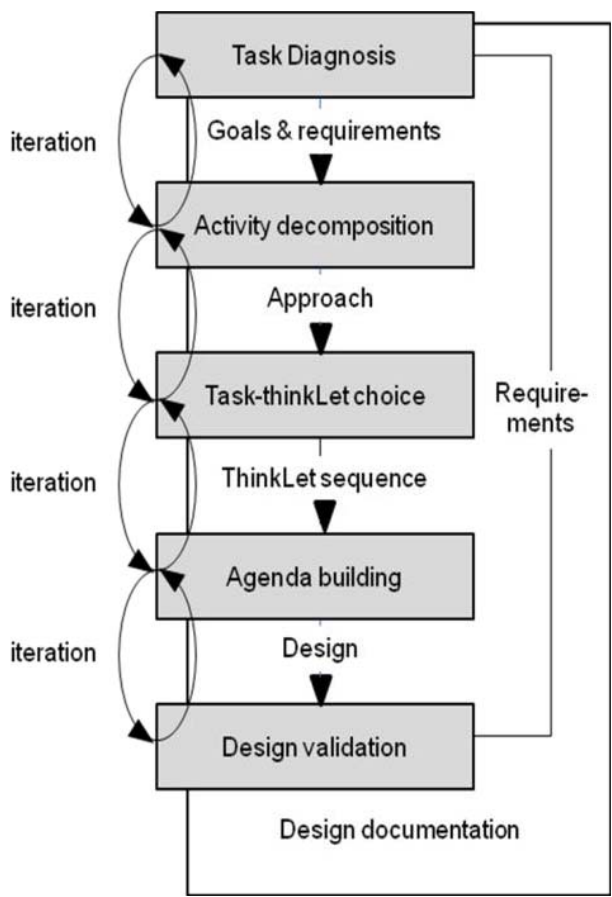

Figure 2: Collaboration Process Design
Approach[22]

Good theory for design is hereby characterized by a model of causal effects, where the phenomenon of interest is the effect (in our case shared understanding), which should be evoked by the means of a design (in our case the collaboration process). The design of collaboration systems used to be more of an art than science for many years and successes or failures where hard to explain and repeat as they were based on intuition and seat-of-the-pants reasoning [25]. It is the aim of collaboration engineering to develop predictable, reusable designs that support a class of recurring work practices. Thus, limited predictability and transferability of unsystematic approaches hinders the contribution of collaboration engineering work. Grounding collaboration system design in rigorous theory can 
help overcome those pitfalls, systematically improve collaboration research over time and point to solutions that are not intuitive [25].

Thus, we used theory based design to ground the design choices for the process on prior theoretical knowledge. Starting with van den Bossches model on learning mechanisms' influence on shared understanding, we deducted general design guidelines for each of the antecedents on which we based our design choices. The design guidelines are used to split the task (constructing shared understanding) into a manageable and repeatable sequence of activities. We validated the process design in a pilot requirements negotiation workshop with experts from different professional backgrounds.

\section{Theoretical Model: Team learning behaviours for the construction of shared understanding}

Grounding on group cognition research from learning sciences and organizational sciences, van den Bossche et al. [21] examined three kinds of team learning behaviours. They tested the effect of construction, co-construction and constructive conflict on the development of shared mental models. Furthermore, they measured, how shared mental models mediate the effect of team learning behaviours on team performance.

Construction of meaning is referred to as "when one of the team members inserts meaning by describing the problem situation and how to deal with it, hereby tuning in to fellow team-members. These fellow team-members are actively listening and trying to grasp the given explanation by using this understanding to give meaning to the situation at hand"'[26].

Collaborative construction (co-construction) is "a mutual process of building meaning by refining, building on, or modifying the original offer in some way" [27]. Construction and co-construction lead to mutual understanding. However, mutual understanding does not yet mean that group members share one perspective or are able to act in a coordinated manner. As our definition of shared understanding involves a "meaning in use" aspect, mutual agreement on one perspective is furthermore necessary to achieve shared understanding.

Mutual agreement is achieved through constructive conflict, "dealing with differences in interpretation between team members by arguments and clarifications" [21]. Following van den Bossche's model, collaborative groups should express, share and listen to their individual understanding (construction), discuss and clarify them to reach mutual understanding (co-construction) as well as controversly negotiate an agreement on a mutually shared perspective (constructive conflict).

\section{Table 1: Theory based design guidelines}

\begin{tabular}{|c|c|c|}
\hline 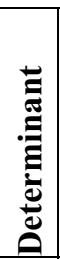 & Item & $\begin{array}{l}\text { Design Guideline } \\
\text { (reflected in } \\
\text { activity) }\end{array}$ \\
\hline \multirow{3}{*}{ 言 } & \multirow[t]{2}{*}{$\begin{array}{l}\text { Team members are } \\
\text { listening carefully to } \\
\text { each other }\end{array}$} & $\begin{array}{l}\text { G1: Express } \\
\text { individual } \\
\text { understandings } \\
\text { first }\end{array}$ \\
\hline & & $\begin{array}{l}\text { G2: Encourage } \\
\text { members to try to } \\
\text { understand each } \\
\text { individual } \\
\text { perspective }\end{array}$ \\
\hline & $\begin{array}{l}\text { If something is unclear, } \\
\text { we ask each other } \\
\text { questions }\end{array}$ & $\begin{array}{l}\text { G3: Ask questions } \\
\text { for clarification }\end{array}$ \\
\hline \multirow{3}{*}{ 童 } & $\begin{array}{l}\text { Information from team } \\
\text { members is } \\
\text { complemented with } \\
\text { information from other } \\
\text { team members }\end{array}$ & $\begin{array}{l}\text { G4: Collect } \\
\text { individual } \\
\text { descriptions in } \\
\text { one shared place }\end{array}$ \\
\hline & $\begin{array}{l}\text { Team members elaborate } \\
\text { on each other's } \\
\text { information and ideas }\end{array}$ & $\begin{array}{l}\text { G5: Evaluate } \\
\text { understanding and } \\
\text { consistency with } \\
\text { own perspective }\end{array}$ \\
\hline & $\begin{array}{l}\text { Team members draw } \\
\text { conclusions from the } \\
\text { ideas that are discussed } \\
\text { in the team }\end{array}$ & $\begin{array}{l}\text { G6: Proceed on } \\
\text { differences } \\
\text { between } \\
\text { understandings } \\
\end{array}$ \\
\hline \multirow{4}{*}{ 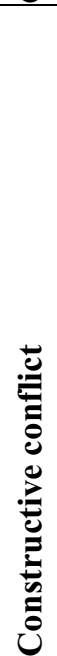 } & $\begin{array}{l}\text { In this team, I share all } \\
\text { relevant information and } \\
\text { ideas I have }\end{array}$ & $\begin{array}{l}\text { G7: Encourage } \\
\text { sharing of } \\
\text { divergent views } \\
\text { (parallel and } \\
\text { anonymous) } \\
\end{array}$ \\
\hline & $\begin{array}{l}\text { This team tends to } \\
\text { handle differences of } \\
\text { opinions by addressing } \\
\text { them directly }\end{array}$ & $\begin{array}{l}\text { G8: Address } \\
\text { differences in } \\
\text { discussion }\end{array}$ \\
\hline & $\begin{array}{l}\text { Comments on ideas are } \\
\text { acted upon }\end{array}$ & $\begin{array}{l}\text { G9: Process every } \\
\text { conflicting aspect }\end{array}$ \\
\hline & $\begin{array}{l}\text { Opinions and ideas of } \\
\text { team members are } \\
\text { verified by asking each } \\
\text { other critical questions }\end{array}$ & $\begin{array}{l}\text { G10: Allow } \\
\text { clarification } \\
\text { questions and } \\
\text { conflict } \\
\text { negotiation } \\
\end{array}$ \\
\hline
\end{tabular}


Van den Bossche et al. found that those team learning behaviours positively influence the construction of shared mental models among students working on a business simulation game. The three team learning mechanisms are operationalized by 9 items, which are displayed in table 1. As construction, coconstruction and constructive conflict should be evoked by the process design, we derived general design guidelines (G1-10) from each item. The process design should reflect those aspects.

\section{Design}

The goal of the collaboration process to be designed is to build a shared understanding of an illdefined group task in heterogeneous work groups at the beginning of group work. In order to design for that goal, we want to evoke the three learning mechanisms construction, co-construction and constructive conflict within the collaboration process. To systematically derive design choices, we first deducted 10 general design guidelines from the operationalized constructs, which are displayed in table 1 .

We splitted the collaboration process into seven activities to reflect the different learning mechanisms (displayed as a Facilitation Process Model [28] in figure 3). The first three activities mainly address construction of meaning. At the beginning of the collaborative process, group members need to make sense of the task individually $(\mathrm{G} 1)$, as it is new to them (A1). In order to allow group members to look into each others' perspectives and develop mutual understanding, the individual conceptions need to be explicitly communicated (A2). We decided for written documentation over spoken words. Written documentation also allows the group to work in parallel (G7) on their descriptions (especially in computer-aided settings) and to return to a text if something is unclear.

The product of A2 is a description of every participant, which reflects his perception of the group task. Those documents are collected in the group support system and serve as an input for the following construction and co-construction efforts, which are carried out mainly in activities three to five.

A3 encompasses dedicated time for reading ("listening" - G2) and clarification of the individual descriptions by questioning (G2, G3). As all participants are encouraged to evaluate the clarity of each description, they are motivated to read each text carefully and reflect on their understanding. Thus, the aspired product of activity three is an understanding of all individual descriptions by all participants. It has to be noted, that those understandings might still differ and mutual agreement has not been reached yet.

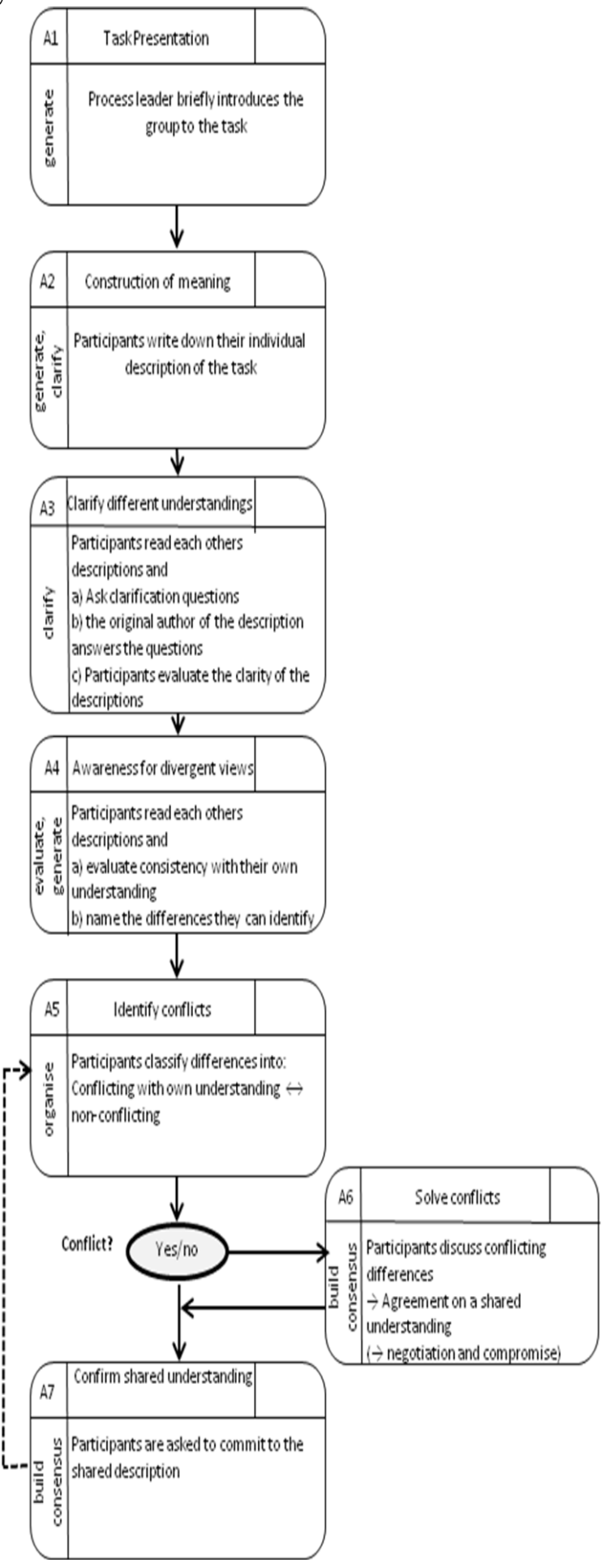

Figure 3: Collaboration process design for shared understanding 
Divergence is identified in A4 as part of the coconstruction phase (G5), where participants evaluate the consistency of each description with their own view and name the differences they observe. This activity is a prerequisite for building a connection between the separate descriptions and converging on one shared description.

The differences are further processed in activity five (A5), where they are categorized into differences that provoke a conflict between the different views and those that can be integrate into a shared perspective without a need to decide for one alternative (G6). The conflicts are solved in a discussion in activity six (A6) (G8, G10).

If a consensus can be reached, it will be included in the shared description, in addition to all nonconflicting aspects. If the participants don't agree initially, a compromise will be negotiated, until a consistent description, reflecting the understanding of the group, results (G9).

The process concludes with another voting activity (A7), asking for the agreement of participants to the shared description. The evaluation results are discussed. If participants still report a lack of shared understanding on the tasks, an iterative loop towards activity five (A5) can be used to solve remaining conflicts (G8, G9). The process has reached its end, as soon as all participants signal commitment to the shared description.

\section{Validation}

Collaboration process designs need to be validated before they should be implemented in practice, preferably combining different validation techniques [29]. Therefore, we first conducted a focus group with three experts on group work and collaboration engineering. Different design alternatives were discussed concerning their expected outcomes, critical points in the process and possible technology to implement them. The main changes after this discussion were some minor adaptions to the wording of the instructions to make them clearer and switching activitites A3 and A4 in the process. The experts agreed, that clarification of the individual understandings should be done before identification of divergent views to avoid misunderstanding and inefficient discussions in the "awareness for divergent views" activity. The process displayed in figure 3 reflects the design after the focus group meeting.

In addition to discussing the design with other researchers in collaboration engineering (expert validation [29]), we conducted a pilot workshop with
11 professionals from different academic and nonacademic backgrounds. The workshop was organized by the authors and observed by a collaboration engineer, instructed to look for weaknesses of the design and unexpected occurrences. The workshop moderator and the observer took field notes, which were discussed afterwards. Comments of the participants, which were related to the collaboration process (e.g. if they found it hard to understand an instruction or mentioned problems with the tool) were documented and interpreted qualitatively by the authors and the observer. Furthermore, noticeable events in the interaction of the participants were treated alike. This pilot implementation should serve as a proof of concept for the collaboration process design and reveal problems and optimization potentials prior to a larger experimental evaluation.

The task for the requirements elicitation workshop was to identify requirements for a digital game based learning application. The game should allow inhabitants of a certain neighbourhood to learn about the history and culture of their surrounding by being navigated between interesting locations in their city and solving little puzzles at those locations. Developers, users, legal experts and project sponsors were invited to contribute their requirements in a 4hour workshop, which was documented on video. Some of the participants knew the project beforehand; others were introduced to the topic at the beginning of the workshop. Group support software Think Tank 3.0 by Group Systems was used to implement the process (note: the general process has been designed independent of technology). After a short introduction, the first one and a half hours of the workshop was used to build a shared understanding of the workshop task, based on the prior modelled process. Table 2 shows a translated version of the instructions and questions given to the participants.

Table 2: Guiding questions for each activity

\begin{tabular}{|l|l|}
\hline & Guiding Questions/Instructions \\
\hline A2 & $\begin{array}{l}\text { Please describe thoroughly the result of this } \\
\text { workshop. What do you imagine [the game] to } \\
\text { look like? }\end{array}$ \\
\hline A3 & $\begin{array}{l}\text { a) Please read through all descriptions of the } \\
\text { other participants and leave a comment on } \\
\text { each aspect you do not understand and would } \\
\text { like to get explained. }\end{array}$ \\
\cline { 2 - 2 } & $\begin{array}{l}\text { b) Briefly answer the questions that refer to } \\
\text { your description of the game to clarify the } \\
\text { point }\end{array}$ \\
\hline
\end{tabular}




\begin{tabular}{|l|l|}
\hline & $\begin{array}{l}\text { c) Please indicate on a five-point-scale for } \\
\text { each of the descriptions (including the } \\
\text { comments on the description), how clear it is } \\
\text { to you (1=very unclear, 5=very clear). }\end{array}$ \\
\hline A4 & $\begin{array}{l}\text { a) Please indicate on a five-point-scale for } \\
\text { each of the descriptions, how much it reflects } \\
\text { your own view on the game (1=I don't agree at } \\
\text { all with the description, 5= I agree } \\
\text { completely). }\end{array}$ \\
\hline & $\begin{array}{l}\text { b) In which aspects do the descriptions differ? } \\
\text { Please write down any differences concerning } \\
\text { the game that you notice. }\end{array}$ \\
\hline A5 & $\begin{array}{l}\text { Please sort the differences you indentified into } \\
\text { conflicting and non-conflicting ones. } \\
\text { Conflicting differences are those which } \\
\text { endanger the success of your group work and } \\
\text { which need to be resolved to come to a } \\
\text { solution. Non-conflicting differences are those, } \\
\text { where both perspectives can be integrated in } \\
\text { the solution. }\end{array}$ \\
\hline A6 & $\begin{array}{l}\text { How should we proceed with the conflicting } \\
\text { differences? Which shared perspective can we } \\
\text { agree on to include in a common description? }\end{array}$ \\
\hline A7 & $\begin{array}{l}\text { Please indicate on a five-point-scale your } \\
\text { perception on how much shared understanding } \\
\text { on the result of this workshop is present in the } \\
\text { group. }\end{array}$ \\
\hline
\end{tabular}

Participants were asked to write a description of what they think the game they would have to specify is about, how it works and what its purpose should be (A1). Activities two to five (A2-A5) were conducted completely within the group support system in a same place same time session. This way, everyone could take the time to read each others' description thoroughly and all written communication was documented in the group support system. Activities six and seven (A6, A7) were done in a moderated group discussion.

At the end of the shared understanding process, participants were asked to fill out a questionnaire on the learning mechanisms and their perceived team effectiveness. This questionnaire was mainly used to examine whether participants face any issues to understand the translated items. However, it can be noted that all constructs were rated above 4,7 on a 7 point Likert Scale on average. Team effectiveness received an average rating of 5,3, which indicates that participants were relatively satisfied with the group work. The team learning behaviour with the highest average rating was construction $(5,9)$, followed by co-construction $(5,8)$ and constructive conflict $(4,7)$. The lower value of constructive conflict might be an indication that constructive conflict might rely on the other two behaviours as a basis and might be more difficult to achieve.

Further investigations should examine this observation. As there was no control group in this initial workshop, results could not be compared. Afterwards, the workshop continued with requirements elicitation activities.

\section{Discussion}

The validation disclosed several potentials for improvement for the process design as well as limitations of the technology in use. First, we noted that participants had problems articulating a thorough description of their understanding of the task in a continuous text in activity A2. Although guiding questions were given that asked for a comprehensive description of the game idea and process, some participants tended to enter unrelated creative ideas for game features or requirements. As those modifications came mostly from participants relatively unfamiliar with the game, we suggest adaptions of the process: A narrower pre-set structure of the description should be given to reduce cognitive load, e.g. "What is the goal of [the game]? How can the game logic be described? Which phases does a player go through when playing [the game]?"

Other representations than plain text should also be tested (e.g. mindmaps or other graphical representations of the content) to make it easier for participants to explicate and structure their knowledge. The suggestion of Saad et al. [30], who propose flexibility in the design of collaboration processes to allow participants to chose and combine different media to express their understanding, using visual as well as semantic representations, should be examined for its applicability for the process discussed here.

Furthermore, people should be given one separate space to write and edit their own description before submitting it in activity A2. This adaption would be consistent with Deshpande et al. [17], who argue that a separation of personal and shared spaces are advantageous to create shared understanding. Submitting each text part immediately (although it could still be edited) shifted the focus away from deep consideration of one's individual description.

Another issue that could be observed was that participants mentioned problems to keep relevant information in mind during activity four (A4). The high cognitive load in activity four, might partially be caused by the group support system, as it did not allow participants to read descriptions, evaluate and take notes on differences in parallel. Thus, group 
members had to keep the difference in mind, which they spotted while reading the texts until they could write them down after the evaluation step. Therefore, in a next instantiation of the process design, it is recommended to implement all actions included in activity four (A4) in a way that participants could switch between actions as they process each description. Thus, while doing the formal evaluation, they should be able to write down each difference they come across.

Difficulties in handling the textual descriptions were further increased by the technical limitations of the tool. The group support system ThinkTank, although very powerful for large lists of short ideas, shows problems when larger text blocks should be displayed and processed. Participants noted that it was hard and non intuitive to read through the texts, as extra windows had to be opened manually to display whole descriptions. We suggest to use alternative tools, which are designed for text processing, for a thorough test of the process. As the collaboration process needs to be evaluated independently of technology, technology support should reflect and not hinder the process design.

\section{Implications, limitations and further research}

We developed a systematic, reusable process to support groups to converge on a shared understanding of a task to be able to collaborate effectively and efficiently. This process design contributes to collaboration engineering research by exploring design opportunities for a crucial process in group work, which still lacks systematic support. The main theoretical contribution of this paper lies in the application of van den Bossches [21] causal model to solve a class of problems, namely to construct shared understanding in hetereogeneous groups through construction, co-construction and constructive conflict.

We derived theory based design guidelines and a process design which helps group work scholars to systematize their research on the construction of shared understanding. If tested in several settings, refined based on our suggestions and documented in a standardized thinkLet format, this process can contribute to collaboration engineering research. ThinkLets for building shared understanding should be developed based on that research to address the lack of reusable and tested procedures for the "clarify" pattern of collaboration.

This paper constitutes a first step in this effort. If the process evokes the causal effects as intended, practitioners can use it to construct a better shared understanding and increase team effectiveness in their collaborative work. Thus, design guidelines and the process design described in this paper contributes to more systematic design for shared understanding in heterogeneous groups.

A limitation is that so far it could not be proven, if the process design is able to evoke the effects it intends to. The validation we did served as a proof of concept and revealed valuable improvement potentials for the process, but the effects on shared understanding and team effectiveness need to be tested in experimental settings with treatment groups following the process and control groups with unstructured group work in future research. Different instances of the process will implemented to test the claim of solving a whole class of problems.

Furthermore, we identified some limitations due to the technology support, which was not able to support all process design choices in an optimal way. Alternative implementations should consider those issues. As shown in the review of related work, shared understanding is a complex construct with various impact factors and effects. Thus, any collaboration process design can only consider selected aspects of shared understanding (in this case, shared understanding of the task) and alternative explanations for changes in shared understanding are hard to control for in complex collaboration processes. Further consideration of this complexity is required as well as research on suitable measurement instruments to analyze shared understanding in field settings.

\section{Acknowledgements}

The research presented in this article was partially funded by the German Federal Ministry of Education and Research in the project TANDEM (www.projekttandem.info), FKZ 01 HH 11089.

\section{References}

1. Langan-Fox, J., J. Anglim, and J.R. Wilson, Mental models, team mental models, and performance: Process, development, and future directions. Human Factors and Ergonomics in Manufacturing, 2004. 14(4): p. 331-352.

2. Mathieu, J.E., et al., The influence of shared mental models on team process and performance. Journal of Applied Psychology, 2000. 85(2): p. 273-283.

3. de Vreede, G.-J., R.O. Briggs, and A.P. Massey, Collaboration Engineering: Foundations and Opportunities: Editorial to the Special Issue on 
the Journal of the Association of Information Systems. Journal of the Association of Information Systems, 2009. 10(Special Issue): p. 121-137.

4. Bowers, C.A., J.A. Pharmer, and E. Salas, When Member Homogeneity is Needed in Work Teams. Small Group Research, 2000. 31(3): p. 305-327.

5. Wegge, J., et al., Age and gender diversity as determinants of performance and health in a public organization: The role of task complexity and group size. Journal of Applied Psychology, 2008. 93(6): p. 1301-1313.

6. Kleinsmann, M., J. Buijs, and R. Valkenburg, Understanding the complexity of knowledge integration in collaborative new product development teams: A case study. Journal of Engineering and Technology Management, 2010. 27(1-2): p. 20-32.

7. Valkenburg, R. and $\mathrm{K}$. Dorst, The reflective practice of design teams. Design Studies, 1998. 19(3): p. 249-271.

8. Darch, P., A. Carusi, and M. Jirotka, Shared understanding of end-users' requirements in eScience projects. E-Science Workshops, 2009 5th IEEE International Conference on, 2009: p. 125128.

9. Mohammed, S. and B.C. Dumville, Team mental models in a team knowledge framework: expanding theory and measurement across disciplinary boundaries. Journal of Organizational Behavior, 2001. 22: p. 89-106.

10. Mohammed, S., L. Ferzandi, and K. Hamilton, Metaphor No More: A 15-Year Review of the Team Mental Model Construct. Journal of Management, 2010. 36(4): p. 876-910.

11. Smart, P.R., et al., Shared Understanding within Military Coalitions: A Definition and Review of Research Challenges, in Knowledge Systems for Coalition Operations. 2009: Southampton.

12. Cannon-Bowers, J.A. and E. Salas, Reflections on shared cognition. Journal of Organizational Behavior, 2001. 22(2): p. 195-202.

13. Mulder, I. and J. Swaak, Assessing group learning and shared understanding in technology-mediated interaction. Educational Technology \& Society, 2002. 5(1): p. 35-47.

14. Hsieh, Y., Culture and Shared Understanding in Distributed Requirements Engineering. International Conference on Global Software Engineering, 2006., 2006: p. 101-108.

15. Kleinsmann, M. and R. Valkenburg, Barriers and enablers for creating shared understanding in codesign projects. Design Studies, 2008. 29(4): p. 369-386.

16. Pascual, R.G., Tools for capturing and training shared understanding in teams. Human Interfaces in Control Rooms, Cockpits and Command Centres, 1999. International Conference on, 1999: p. 57-63.

17. Deshpande, N., B. Vries, and J.P. van Leeuwen, Building and supporting shared understanding in collaborative problem-solving. Information Visualisation, 2005. Proceedings. Ninth International Conference on, 2005: p. 737-742.

18. Du, J., S. Jing, and J. Liu, Shared design thinking process model for supporting collaborative design. Computer Supported Cooperative Work in Design (CSCWD), 2010 14th International Conference on, 2010: p. 65-70.

19. Jeong, H. and M. Chi, Knowledge convergence and collaborative learning. Instructional Science, 2007. 35(4): p. 287-315.

20. Fischer, F. and H. Mandl, Knowledge Convergence in Computer-Supported Collaborative Learning: The Role of External Representation Tools. The Journal of the Learning Sciences, 2005. 14(3): p. 405-441.

21. Van den Bossche, P., et al., Team learning: building shared mental models. Instructional Science, 2011. 39(3): p. 283-301.

22. Kolfschoten, G. and G.-J. de Vreede, The Collaboration Engineering Approach for Designing Collaboration Processes

Groupware: Design, Implementation, and Use, J. Haake, S. Ochoa, and A. Cechich, Editors. 2007, Springer Berlin / Heidelberg. p. 95-110.

23. Briggs, R.O. and G.-J. de Vreede, ThinkLets: Building Blocks for Concerted Collaboration. . 2009, Omaha.

24. Briggs, R.O., et al., Defining Key Concepts for Collaboration Engineering, in AMCIS 2006. 2006.

25. Briggs, R.O., On theory-driven design and deployment of collaboration systems. International Journal of Human-Computer Studies, 2006. 64: p. 573-582.

26. Webb, N.M. and A.S. Palincsar, Group processes in the classroom, in Handbook of educational psychology, D.C. Berliner and R.C. Calfee, Editors. 1996: New York.

27. Baker, M., A model for negotiation in teachinglearning dialogues. Journal of Artificial Intelligence in Education, 1994. 5(2): p. 199-254.

28. De Vreede, G.-J. and R.O. Briggs, Collaboration Engineering: Designing Repeatable Processes for High-Value Collaborative Tasks, in 38th Hawaii International Conference on System Sciences. 2005.

29. Kolfschoten, G. and G.-J. De Vreede, A Design Approach for Collaboration Processes: A MultiMethod Design Science Study in Collaboration Engineering. Journal of Management Information Systems, 2009. 26(1): p. 225 - 256

30. Saad, M. and M.L. Maher, Shared understanding in computer-supported collaborative design. Computer-Aided Design, 1996. 28(3): p. 183192. 